Revista de Economia Política, vol. 31, $n^{\circ} 1$ (121), pp. 77-97 janeiro-março/2011

\title{
Cooperação monetária e financeira: o que é bom para a Ásia também é para a América Latina?
}

\author{
RENATO BAUMANN* \\ CARLOS MUSSI
}

Monetary and financial cooperation: what is good to Asian is also good to Latin America?. This article compares the Asian and Latin American experiences with monetary cooperation. It is argued that in the latter such cooperation has hardly progressed, due to low degree of regional integration, the recurrent use of multilateral institutional resources to deal with external shocks and the lack of clear objectives: monetary cooperation is some times seen as a means to foster integration, but also as a means to provide long term funds and as a source of liquidity in foreign currencies. In Asia, differently, cooperation has apparently not been so instrumental to regional integration, but has proven to be quite important as a means to build a regional capital market as well as a mechanism to deal with external shocks.

Keywords: monetary cooperation; Latin America.

JEL classification: F 15; F 36.

\section{INTRODUÇÃO}

As economias da América Latina apresentaram resultados positivos entre 2003 e 2008: taxas de crescimento da produção a níveis razoáveis, geração de postos de trabalho de melhor qualidade, prudência na gestão fiscal, superávits em Conta-corrente, menor endividamento e melhor qualidade da dívida, e acumulação de ativos externos. No entanto, elas não estão imunes a turbulências no mercado internacional. A partir do momento em que os efeitos da crise de

\footnotetext{
* Respectivamente, técnico do Ipea, ex-funcionário da Cepal, e-mail: renatobauma@gmail.com; funcionário do Escritório da CEPAL no Brasil. E-mail: carlos.mussi@cepal.org. As opiniões expressas aqui são de responsabilidade pessoal, e podem não corresponder à posição das instituições. Agradecemos as sugestões de dois leitores anônimos desta Revista. Submetido: Dezembro 2008; Aprovado: Setembro 2009.
} 
2008 começaram a se fazer sentir, os governos da região consideraram alternativas de defesa. Entre outras, o aprofundamento das transações regionais.

O tema da cooperação monetária na região sempre esteve, direta ou indiretamente, associado às preocupações com intensificar o processo de integração regional: houve algum avanço na provisão de liquidez via fundos regionais, houve resultados positivos no uso de mecanismo de crédito recíproco, e o debate sobre a criação de mecanismos para financiamentos a longo prazo reflete a preocupação em superar as deficiências de infraestrutura que dificultam o comércio regional.

Ao mesmo tempo, as análises sobre a aproximação entre as economias emergentes da Ásia reconhecem que tradicionalmente essa região resistiu à formalização de acordos de preferências comerciais. No entanto, os processos de complementaridade produtiva mostram já há algum tempo uma intensidade expressiva.

Essa associação entre importância nas transações intrarregionais e convergência monetária e financeira reforça a leitura crítica da experiência latino-americana. Passaram a ser frequentes as recomendações de que a promoção da cooperação monetária deve ser adotada de forma simultânea à consolidação das preferências comerciais.

Não é claro em que momento a promoção da convergência das políticas monetárias deve começar, qual tipo de instrumento é mais recomendado para cada caso, que grau de profundidade deve ser buscado nessa convergência, e quais os critérios a serem seguidos para a eleição dos parceiros com os quais promover esse processo. A teoria de integração monetária é de utilidade apenas parcial, nesse sentido.

Para uma região com as características da América Latina - infraestrutura inadequada e insuficiência de poupança e de mecanismos de financiamento de longo prazo - não é claro se os esforços devem se concentrar, em sua fase inicial, na constituição de mecanismos de provisão de liquidez para situações de escassez de divisas, ou se a aposta deve ser nos instrumentos para o financiamento de projetos de maior envergadura.

De todo modo, é reconhecido (Ocampo, 2006) que a cooperação entre países vizinhos pode ser eficaz em casos de crise. Portanto, os países de menor renda deveriam buscar essa complementariedade com os parceiros maiores para conseguir financiamento em larga escala.

Ambas carências levam à recomendação de se estimular um mercado regional de capitais. No entanto, a carência predominante - a falta de clareza de propósitos quanto ao processo de integração - tem levado a uma razoável dispersão de propostas e de iniciativas.

A partir dessas inquietudes, neste artigo nós procedemos a uma análise comparada das situações encontradas nos países da Ásia e da América Latina. À diferença da América Latina, as iniciativas dos países asiáticos para a promoção da cooperação monetária e financeira têm sido motivadas muito mais 
pelos traumas causados pelos choques externos que por esforços para promover a integração regional.

São três os argumentos enfatizados aqui. Primeiro, nos últimos 25 anos os países da América Latina buscaram apoio financeiro expressivo junto ao Fundo Monetário Internacional, entre outras fontes multilaterais, enquanto entre os asiáticos esse recurso foi menos explorado. Isso explica a preocupação asiática em constituir fundos regionais para ajudar nas situações de choques externos, enquanto as propostas de cooperação financeira latino-americanas têm enfatizado outras preocupações, como a facilitação dos processos de integração comercial. São duas lógicas distintas.

Segundo, a existência de mecanismos de cooperação monetária é provavelmente uma condição necessária para o aprofundamento e a consolidação do processo de integração regional, mas não uma condição suficiente. As indicações de grau de envolvimento com o comércio regional por parte dos países asiáticos sugerem que outros elementos são mais determinantes. A importância relativa do comércio regional, bastante expressiva, pouco se alterou em função da introdução dos mecanismos de cooperação monetária.

Terceiro, não é preciso percorrer todas as modalidades de integração para se começar a evoluir na direção de uma cooperação monetária. A análise teórica convencional que estabelece uma taxonomia sequencial de processos de integração considera a dimensão monetária apenas num estágio superior. De fato, essa tem sido a prática mais comum na América Latina - negociações de preferências comerciais são independentes e serão seguidas no futuro de acordos na área monetária. No entanto, mesmo níveis mais baixos de integração podem ser afetados de forma negativa na inexistência de mecanismos de cooperação monetária. A experiência dos efeitos, para o Mercosul, da desvalorização não negociada da moeda brasileira em 1999 é um exemplo claro disso.

Este artigo está estruturado da seguinte forma. A próxima seção discute a relação entre integração regional e cooperação monetária, enfatizando alguns aspectos relativos ao sequenciamento mais adequado dos dois processos. A terceira seção relata a experiência asiática. Na quarta seção mostramos como tem evoluído a experiência latino-americana em relação à convergência financeira. A quinta seção mostra alguns indicadores relevantes, comparando os contextos encontrados nas duas regiões, e a sexta seção traz as considerações finais.

\section{A RELAÇÃO ENTRE INTEGRAÇÃO REGIONAL E INTEGRAÇÃO MONETÁRIA}

A literatura teórica relacionada com processos de integração trata de modo isolado os processos comerciais e a integração monetária. No caso das preferências comerciais os níveis seguem uma sequência taxonômica, de acordos de preferências localizadas à criação de um mercado comum. Na conver- 
gência monetária a evolução vai da coordenação das políticas cambiais à integração monetária plena, com adoção de moeda única. São tratamentos em paralelo.

A teoria considera uma sequência 'natural' para os processos de integração, começando com preferências comerciais e apenas num momento posterior a negociação relativa à convergência monetária: como resultado da integração comercial haverá convergência nos padrões de demanda dos diversos parceiros, portanto maior sintonia de ciclos de atividade, o que cria um ambiente mais propício para a coordenação monetária.

Essa sequência tem sido questionada. A coordenação monetária pode ser de fato um instrumento promotor do processo de integração comercial, invertendo-se a lógica anterior.

Tanto a literatura sobre integração comercial como a teoria sobre integração monetária propõem critérios para a identificação ex-ante dos parceiros mais adequados para os processos de integração.

No caso dos acordos comerciais a recomendação ${ }^{1}$ é de complementaridade com países de estruturas produtivas (e padrões de demanda) semelhantes, já que isso maximiza as oportunidades para a criação de comércio.

A teoria das áreas monetárias ótimas enfatiza ${ }^{2}$ ademais o grau de interação comercial entre os parceiros, o grau de abertura das economias participantes, e o grau de mobilidade dos fatores de produção entre os países que fixarão suas moedas de modo bilateral. São critérios distintos.

Rajan (2002) propõe quatro motivos para essa inversão de sequenciamento: i) as estruturas produtivas podem se tornar vulneráveis a choques assimétricos de oferta, e haveria necessidade de alterar paridades para compensar tais choques; ii) uma moeda comum pode estimular as transações entre parceiros (como propõe a teoria de áreas monetárias ótimas); iii) um processo de integração pode ser minado pela instabilidade das paridades entre os países-membros; iv) dada a dimensão política da integração, é provável que a aproximação comercial anteceda a coordenação monetária, mas em situações traumáticas pode ser dada prioridade à cooperação monetária.

Sobretudo nos países com dívida elevada em moeda estrangeira ${ }^{3}$ não há razão para a integração comercial anteceder a integração monetária (Fritz \& Mühlich, 2006): com choque externo esses países tendem a desvalorizar suas moedas, o que pode afetar os processos de integração.

Para Culpeper (2006) outra razão para a cooperação monetária está relacionada com a compensação de mercados incompletos. A isso se agrega a

\footnotetext{
${ }^{1}$ As referências clássicas são Lipsey (1960) e Cooper \& Massell (1965).

${ }^{2}$ Ver, por exemplo, De Grauwe (1992) e Ishiyama (1975).

${ }^{3}$ O chamado 'pecado original', segundo Eichengreen \& Hausmann (1999): a incapacidade do país emitir títulos no mercado internacional em sua própria moeda.
} 
'economia política' das instituições multilaterais, cujas decisões nem sempre correspondem aos interesses imediatos das economias em desenvolvimento.

$\mathrm{Na}$ América Latina tem havido clara opção pelas preferências comerciais, e tentativas esporádicas de criação de mecanismos de cooperação monetária, mas com propósitos diversos: ora são mecanismos de 'clearing', ora instrumentos de provisão de crédito de longo prazo, ou mesmo ferramentas para a provisão de liquidez de divisas. Esses instrumentos são complementares, mas os objetivos que procuram atingir não são facilmente identificáveis em forma conjunta a priori, e é frequente a sua descontinuidade. O grau reduzido de interação comercial entre os países é um complicador para a promoção da cooperação monetária. Ao mesmo tempo, a multiplicidade de objetivos quando se propõem mecanismos de cooperação é um obstáculo adicional para sua concretização.

Nos países asiáticos, diferentemente, os esforços de alinhamento das ações das autoridades monetárias são mais nítidos e os objetivos mais explícitos. Ali a cooperação monetária foi claramente estimulada a partir do trauma de choques externos.

\section{A EXPERIÊNCIA ASIÁTICA}

Esta seção apresenta as iniciativas mais expressivas adotadas pelos países asiáticos, na promoção da cooperação monetária e financeira. Para ilustrar a crescente importância atribuída ao tema por parte desses países, a descrição dos instrumentos adotados para tanto é feita em função dos tipos de medidas consideradas.

\section{Banco de desenvolvimento}

A região conta com um banco de desenvolvimento, o Asian Development Bank, criado em 1966 e com sede em Manila, Filipinas. São 67 países-membros, dos quais 48 países da região. O banco tem uma cotação no mercado de 'triplo A', o que lhe permite captar recursos a custos reduzidos, e suas operações são predominantemente com o setor público dos países.

Como ficará claro na próxima seção, a existência de um único banco de desenvolvimento regional, com baixa classificação de risco, é uma diferença importante em relação à experiência da América Latina.

\section{Fundos de liquidez}

Em 1977, em vista dos efeitos da primeira elevação dos preços do petróleo, dos ajustes provocados por ela e da crescente movimentação financeira, o Japão propôs a criação de um fundo de US\$ 100 bilhões, para prover liquidez e neutralizar ataques especulativos. A ideia foi descartada, com o argumento 
de que isso duplicaria de forma desnecessária os recursos do FMI e poderia dar origem a problemas de risco moral.

Quando estourou a crise em 1997 o total de financiamento requerido para restabelecer a estabilidade financeira na Coreia, Tailândia e Indonésia chegou a quase US\$ 112 bilhões. Naquele momento o FMI teve dificuldade para dispor desse volume de recursos e foi necessário o apoio adicional dos países mais ricos, já que tampouco existia alternativa regional. O Japão propôs novamente a criação de um Fundo Monetário asiático, mas a ideia não prosperou.

Ainda em 1997 cinco países da ASEAN ${ }^{4}$ concordaram em estabelecer um Acordo Ampliado para Swaps (ASA), para prover liquidez aos países participantes com problemas de Balanço de Pagamentos. ${ }^{5}$ Tratava-se de um mecanismo para complementar os recursos do FMI na assistência a ajustes estruturais.

O encontro do ASEAN de Maio de 2000 na cidade de Chiang Mai, na Tailândia, marcou o lançamento e detalhamento inicial do que ficou conhecido como Iniciativa de Chiang Mai, que permitiu a expansão do Arranjo de Swap da ASEAN e a criação de bases para o estabelecimento de swaps cambiais bilaterais e acordos de recompra.

As principais características da Iniciativa de Chiang Mai são: i) um acordo de Swap, incluindo todos os países da ASEAN, e um conjunto de swaps bilaterais e acordos de facilidades de recompra entre os países membros da ASEAN + 3; ii) intercâmbio de dados e informações sobre fluxos de capitais; iii) um acordo regional de financiamento para complementar as facilidades internacionais existentes; iv) o estabelecimento de mecanismo de alerta prévio em relação a desajustes conjunturais.

Além disso, foram estabelecidos: i) troca de informações econômicas, especialmente sobre os fluxos de capital entre os países participantes; ii) estabelecimento de uma rede de contatos para facilitar o monitoramento e coordenação das ações; iii) criação de um arranjo financeiro suplementar às facilidades já disponíveis pelas agências multilaterais.

Em 2002 o ASEAN+36 ${ }^{6}$ mais quatro países ${ }^{7}$ lançaram o Diálogo de Cooperação da Ásia, fortalecendo o apoio mútuo em diversas áreas, sobretudo a retenção da poupança gerada na região, numa coordenação de várias iniciativas articuladas com outras organizações regionais no desenvolvimento

\footnotetext{
${ }^{4}$ Indonésia, Malásia, Filipinas, Cingapura e Tailândia.

${ }^{5}$ No ASA podem ser usados, além do dólar, o ien e o euro, e a taxa de referência é a LIBOR, para operações em euro. O volume máximo que cada participante pode retirar é limitado a duas vezes sua contribuição ao ASA. Uma transação ASA tem maturidade máxima de seis meses, com possibilidade de prorrogação por mais seis meses.

${ }^{6}$ Países membros do ASEAN (Brunei, Camboja, Cingapura, Filipinas, Indonésia, Laos, Malásia, Miamar, Tailândia e Vietnã) mais China, Coreia do Sul e Japão.

${ }^{7}$ Isto é, Bahrein, Bangladesh, Catar e Paquistão.
} 
da infraestrutura de mercado, de fundos de investimento e estruturação de novos instrumentos e produtos financeiros.

Em 2003, na reunião do EMEAP $^{8}$ (Encontro de Executivos dos Bancos Centrais do Leste Asiático e Pacífico) foi criado um Fundo de Títulos Asiáticos (Asian Bond Fund Initiative - ABFI), com uma dotação inicial de US\$ 1 bilhão. São nove fundos participantes, sendo um regional, o Pan-Asia Bond Index Fund, e oito fundos de países.

\section{Uso compartilhado de reservas}

Em 1995 o EMEAP criou um pacote de acordos de recompras bilaterais de papéis do Tesouro americano, com o objetivo de prover liquidez de divisas.

$\mathrm{Na}$ primeira fase da Iniciativa de Chiang Mai os montantes envolvidos (US\$ 36,5 bilhões) mostraram ser insuficientes para lidar com movimentos especulativos, tendo em vista as reservas de divisas do conjunto dos países (US\$ 1,8 trilhão) e o volume de recursos requeridos para assistência aos países afetados (Sohn, 2007). Em 2008 esses acordos compreendiam um volume recursos de US\$ 83 bilhões (Volz, 2008).

O Acordo Ampliado ASEAN para Swap (ASA) e a Rede de Swaps Bilaterais e Acordos de Recompra (BSA), ${ }^{9}$ foram aprovados em 2001 (Park, 2006). A BSA é complementar aos programas do FMI, já que os países que usam essa facilidade têm de cumprir programa de ajuste macroeconômico e estrutural indicado pelo Fundo. ${ }^{10}$

O sucesso da recuperação econômica da região permitiu uma sensível redução da vulnerabilidade externa, levando a outro problema: o excesso de poupança. A criação da ABFI procura estimular a aplicação, na região, das reservas asiáticas tradicionalmente aplicadas na Europa e EUA, assim como proteger os países da região contra choques externos.

Essa busca de fortaleza na complementaridade regional tem paralelo no lado comercial: os países asiáticos têm de competir não apenas entre si, mas também com a concorrência por parte dos EUA, China e Japão. A opção por fortalecer o regionalismo financeiro e comercial reflete o entendimento de que essa complementaridade fortalece o potencial competitivo dos países da região (Heidrich, 2008).

Em 2008 os ministros de finanças dos países do ASEAN + 3 decidiram

\footnotetext{
${ }^{8}$ Compreende representantes da Austrália, China, Hong Kong, Indonésia, Japão, Malásia, Nova Zelândia, Filipinas, Coreia, Cingapura e Tailândia.

${ }^{9}$ A BSA é uma facilidade destinada a prover liquidez de curto prazo em forma de swaps de dólares por moedas nacionais dos países participantes. Em 2007 o volume de transações através da BSA superou os US\$ 70 bilhões.

${ }^{10}$ O BSA permite, contudo, um desembolso de até $10 \%$ do montante máximo de saque sem qualquer vínculo com programa do FMI.
} 
que ao menos US\$ 80 bilhões das reservas da região passarão a compor um fundo para proteger as moedas nacionais contra ataques especulativos. Desses recursos $80 \%$ serão originários da China, Japão e Coreia. Essa iniciativa é semelhante à proposta japonesa de 1997, quando foi proposta a criação de um Fundo Monetário Asiático (Volz, 2008).

\section{Mecanismos de consulta}

Nos anos 1950 o principal fórum para discussões entre bancos centrais asiáticos era o SEANZA, ${ }^{11}$ com foco na capacitação de banqueiros centrais. Outro fórum de bancos centrais foi criado em 1966, o SEACEN (Bancos Centrais do Sudeste Asiático, com 10 países-membros) também com foco centrado em treinamento e pesquisa.

Em 1998 os Ministros de Finanças da ASEAN estabeleceram o Processo de Monitoramento da ASEAN. Além de monitorar as taxas de câmbio e os agregados macroeconômicos, o ASP acompanha as políticas sociais e setoriais, assim como provê capacitação, fortalecimento institucional e troca de informações.

Em 2006 o ASEAN + 3 criou um Grupo de Especialistas (GOE) e um Grupo de Trabalho Técnico em Monitoramento Econômico e Financeiro (ETWG) para fortalecer a capacidade de monitoramento.

\section{ALGO SOBRE A COOPERAÇÃO MONETÁRIA NA AMÉRICA LATINA}

O tema da cooperação monetária está presente há várias décadas na América Latina. ${ }^{12}$ A região sempre teve vínculos comerciais predominantes com os principais centros econômicos. Como descrito por Prebisch (1987), a abundância ou escassez de divisas definia os ciclos dessas economias. A criação dos Bancos Centrais na região, em sua maior parte nas décadas de 1920 e 1930, estabeleceu mecanismo institucional para um diálogo sobre cooperação técnica, e posteriormente sobre colaboração financeira.

Com as discussões sobre novos arranjos cambiais e monetários em Bretton Woods e a criação dos organismos multilaterais, consolidou-se nova estrutura de financiamento internacional, com um comércio com menos restrições que nas décadas anteriores. Esse sistema deveria reduzir a prática dos países latino-americanos de renegociar as suas dívidas externas diretamente com a banca privada ou com um governo específico.

Ao mesmo tempo, a região estava interessada em ampliar sua capacidade produtiva e ansiava ter acesso à ajuda externa, para financiar novos projetos de investimentos com poupança externa. Assim, a cooperação financeira com-

\footnotetext{
${ }^{11}$ Sudeste Asiático, Nova Zelândia e Austrália, num total de 18 países-membros.

${ }^{12}$ Ver, a propósito, Nussbaum (1944).
} 
preendia o financiamento tanto do Balanço de Pagamentos quanto dos investimentos produtivos.

Para facilitar a comparação com a experiência asiática são apresentados a seguir os principais instrumentos disponíveis na América Latina.

\section{Bancos de desenvolvimento}

A primeira tentativa de se criar um banco interamericano ocorreu numa conferência em Washington, em 1890, quando não se conseguiu convencer os Estados Unidos da conveniência de uma instituição desse tipo. Em 1940 foi firmado um convênio para a criação de um banco interamericano, mas o conflito mundial anulou a iniciativa (Culpeper, 2006). Finalmente, o Banco Interamericano de Desenvolvimento foi criado em 1959, seguido do Banco Centro-americano de Integração Econômica (BCIE) ${ }^{13}$ dez anos depois. ${ }^{14}$

Em 1970 foi criado o Banco de Desenvolvimento do Caribe. No mesmo ano foi criada a Corporação Andina de Fomento, uma das instituições financeiras mais destacadas da região, com volume de empréstimos aos países da região que supera em valor as operações do BID e do Banco Mundial com esses países.

Em 1978 foi criado o Banco Latino-Americano de Exportações, custeado por aportes dos Bancos Centrais da região, entre outros, e com os objetivos de capitalizar outros bancos na região e financiar o comércio exterior na América Latina.

Existe, portanto, na América Latina, uma diversidade institucional mais pronunciada do que é encontrado na Ásia.

\section{Fundos de liquidez}

Os anos 1960 trouxeram dificuldades para o financiamento do balanço de pagamentos da região. Os preços das commodities regrediram aos seus menores níveis, desde a Grande Depressão. Como resultado, procurou-se estabelecer um mecanismo de estímulo ao comércio intrarregional, com o Acordo de Pagamentos e Crédito Recíproco.

O Acordo de Pagamento e Crédito Recíproco foi assinado pelos Bancos Centrais no âmbito da ALADI em 1965. ${ }^{15}$ Trata-se de mecanismo de compensação (a cada quatro meses) dos créditos e débitos entre os Bancos Centrais dos países participantes (membros da ALADI, menos Cuba, e mais República Dominicana).

\footnotetext{
${ }^{13}$ Segundo Culpeper (2006) todos os bancos regionais de desenvolvimento - na América Latina como na África e posteriormente na Europa - foram criados com o propósito de apoiar a integração regional. Apesar disso, essa parte de seu mandato só correspondeu a uma parcela diminuta de sua atuação.

${ }^{14} \mathrm{O}$ que situa o BID como o primeiro banco de desenvolvimento regional.

${ }^{15}$ Em moldes semelhantes ao da União Europeia de Pagamentos, criada em 1950.
} 
Como mostra o Gráfico 1 a seguir, a importância desse mecanismo atingiu seu ponto de máximo em 1989, quando $90 \%$ das transações regionais foram feitas por seu intermédio, sendo virtualmente eliminado - por razões de mudanças na sua fonte de operação e em vista do excesso de liquidez de divisas na região - no início da presente década. Tem havido uma tímida recuperação nos últimos anos, mas claramente em níveis bem mais reduzidos que antes.

Gráfico 1: Participação (\%) das Operações sob Convênio de Crédito Recíproco no Total das Exportações Intrarregionais Latino-Americanas — 1965-2007

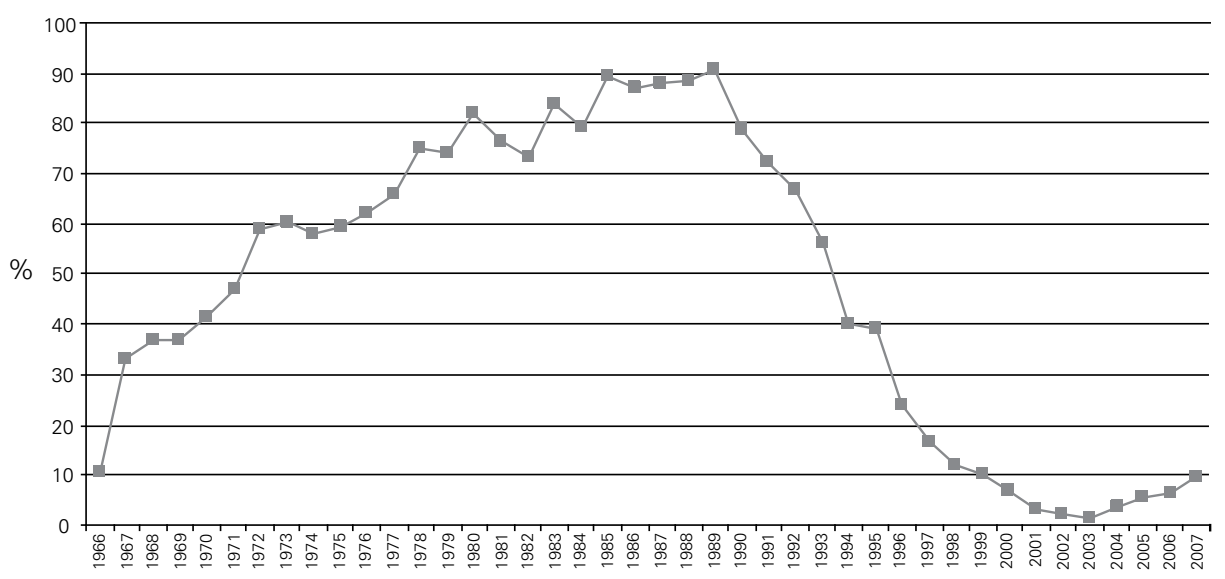

Fonte: ALADI; dados disponíveis em http://www.aladi.org/nsfaladi/convenio.nsf/inicio2004.

Entre 1966 e 2004 o CCR possibilitou que quase 1/4 do comércio regional fosse feito sem transferência de divisas entre Bancos Centrais, ${ }^{16}$ o que pode ser considerado de fato como um 'swap' efetivo entre os países participantes do sistema, que antecedeu em muito a Iniciativa Chiang Mai asiática.

Mais recentemente, Brasil e Argentina passaram a admitir o uso de moedas nacionais para as transações comerciais bilaterais. Depois de um longo período de adaptação de normas passou a vigorar a partir de outubro de 2008 a possibilidade sem precedentes na região de realizar intercâmbio comercial nas moedas dos dois países (além das transações em divisas fortes).

\section{Uso compartilhado de reservas}

Em 1969 os países Centro-Americanos criaram um Fundo Centro-Americano de Esterilização Monetária, complementar ao FMI, para financiar dese-

\footnotetext{
${ }^{16}$ Estimado como o total das operações realizadas no âmbito do CCR no período (US\$ 216 bilhões) menos as divisas transferidas (US\$ 67 bilhões), em relação ao total das importações intrarregionais (US\$ 683 bilhões), a partir de dados disponíveis em Ruttimann e outros (2008). Estimativas semelhantes são encontradas em UNCTAD (2007).
} 
quilíbrios do Balanço de Pagamentos. As operações desse Fundo foram descontinuadas na década de 1970 , em vista de dificuldades de financiamento (UNCTAD, 2007).

Em 1978 foi criado o Fundo Latino-Americano de Reservas (FLAR), um fundo comum de reservas internacionais dos países andinos (que desde 1988 também inclui a Costa Rica). Esse fundo teve papel importante na provisão de recursos em caráter emergencial, sobretudo no período de crise da dívida externa (década de 1980). Do mesmo modo que o CCR, pode-se argumentar que é um fundo regional que antecede em 22 anos a Iniciativa Chiang Mai.

\section{Mecanismos de consulta}

O Tratado de Montevidéu de 1960, que criou a ALALC, tem como uma de suas resoluções anexas a convocação, pela CEPAL, de uma reunião de Bancos Centrais dos países-membros para "estudios sobre créditos y pagos que faciliten la financiación de las transacciones en la Zona de Libre Comercio".

Em 1952 foi criado o Centro de Estudos Monetários Latino-Americanos, CEMLA, por meio do qual os bancos centrais da região puderam realizar capacitação e estudos conjuntos, assim como receber a colaboração de organismos internacionais, como a CEPAL, FMI, BID e outras instituições.

Mais recentemente os diversos exercícios de integração sub-regional têm se empenhado em criar espaços nos quais as autoridades dos países participantes possam sistematizar informações e intercambiar experiências. No caso do Mercosul, os Sub-Grupos de Trabalho 4 (Assuntos financeiros) e 14 (Seguimento da conjuntura econômica e comercial) são dois exemplos, e algum esforço tem sido feito na homogeneização dos dados dos países-membros. Mas resta ainda um bom caminho a percorrer para que se possa aproximar dos padrões de convergência encontrados nos países asiáticos.

\section{ALGUNS INDICADORES RELEVANTES NA COMPARAÇÃO ENTRE AS DUAS REGIÕES}

Para a comparação das duas regiões serão considerados aqui dois conjuntos de 14 países. Esses países correspondem, em ambos casos, a mais de $90 \%$ do produto regional. Uma primeira dimensão notável no caso dos países asiáticos (Tabela 1) é o grau de interdependência das economias participantes desses esforços. Desde 1990 o comércio intrarregional ${ }^{17}$ correspondeu em média a mais de uma terça parte das exportações totais dos 14 países considerados, e essa participação tem sido mantida sem grandes oscilações.

\footnotetext{
${ }^{17}$ Entendido como o conjunto das transações entre esses 14 países.
} 
Tabela 1: Participação (\%) do Mercado Regional nas Exportações Totais

\begin{tabular}{|c|c|c|c|c|c|c|c|}
\hline & & $(\%)$ & & & & $(\%)$ & \\
\hline & 1990 & 2000 & 2006 & & 1990 & 2000 & 2006 \\
\hline Brunei & 91,6 & n.d. & 77,7 & Argentina & 25,3 & 47,1 & 40,4 \\
\hline Camboja & n.d. & 8,2 & n.d. & Bolívia & 44,8 & 43,6 & 64,2 \\
\hline China & 23,7 & 29,1 & 23,4 & Brasil & 10,2 & 23,6 & 23,1 \\
\hline Cingapura & 37,5 & 44,7 & 52,4 & Chile & 11,9 & 20,3 & 15,4 \\
\hline Coreia & 30,4 & 35,3 & 41,3 & Colômbia & 9,5 & 22,2 & 21,3 \\
\hline Filipinas & 30,7 & 35,5 & 47,1 & C.Rica & 8,9 & 12,1 & 10,0 \\
\hline Índia & 15,8 & 13,9 & 21,9 & Guatemala & 15,9 & 23,5 & 25,4 \\
\hline Indonésia & 61,5 & 54,2 & 29,9 & Honduras & 3,2 & 13,4 & 11,7 \\
\hline Japão & 20,7 & 27,7 & 34,9 & México & 4,2 & 2,3 & 4,0 \\
\hline Laos & n.d. & n.d. & n.d. & Nicarágua & 18,6 & 18,2 & 16,5 \\
\hline Malásia & 54,2 & 48,4 & 49,5 & Paraguai & 44,5 & 74,4 & 59,0 \\
\hline Paquistão & 18,5 & 12,7 & 8,8 & Peru & 12,7 & 15,6 & 16,5 \\
\hline Tailândia & 32,6 & 41,0 & 46,5 & Uruguai & 39,2 & 53,2 & 34,9 \\
\hline Vietnam & n.d. & 49,3 & 40,0 & Venezuela & 8,5 & 14,1 & 6,1 \\
\hline Média(*) & 37,9 & 33,3 & 39,5 & & 18,4 & 27,4 & 24,9 \\
\hline
\end{tabular}

Fonte: UN/COMTRADE

$\left({ }^{*}\right)$ média não ponderada

Chama a atenção, em particular, o peso das transações no mercado regional para as exportações de Brunei e Cingapura, acima dos 50\% em 2006. E para metade dos países considerados essa participação era, nesse ano, superior aos $40 \%$.

Esses números por si sós não permitem avaliar de forma clara a evolução das transações intrarregionais: houve aumento expressivo no peso dessas transações nos casos de Cingapura, Coreia, Filipinas, Índia, Japão e Tailândia, redução pronunciada nos casos da Indonésia e Paquistão e relativa estabilidade nos percentuais relativos à China e Malásia. Não é possível, portanto, uma afirmativa categórica, a este nível de análise, sobre se as medidas de coordenação adotadas a partir de 1997 tiveram impacto decisivo sobre a intensidade do comércio intrarregional.

No entanto, os indicadores de relativa constância na participação média das exportações regionais no total exportado pelos países da Ásia num período - como se verá - de marcante aumento da importância do mercado regional de capitais e outros mecanismos de cooperação financeira faz crer que essa cooperação não parece ter tido efeito pronunciado sobre a intensidade do processo de integração regional.

Esses percentuais asiáticos estão bem acima daqueles registrados no comércio entre os países da América Latina: em 2006 o mercado regional correspondia (Tabela 1 ) a apenas $25 \%$ das exportações totais dos países da região, com um grau elevado de dispersão (4,0\% no caso do México; $64,2 \%$ no caso da Bolívia), e abaixo dos $27 \%$ de comércio intrarregional registrado em 2000.

Quanto mais expressivo o peso das transações comerciais com os países vizinhos maior será o interesse em promover a convergência macroeconômica, 
uma vez que o impacto de eventuais desequilíbrios nas relações bilaterais é mais intenso. Isso explica em grande medida o empenho dos países asiáticos em promover cooperação monetária e financeira.

Por outro lado, o fato de já apresentar um grau de integração nos fluxos de comércio intrarregionais relativamente elevado e estável sugere que a cooperação financeira entre os países asiáticos não deve ter sido concebida - à diferença do caso latino-americano - como uma ferramenta para a promoção da integração.

No caso dos países latino-americanos essa cooperação tem sido pensada em forma distinta, com propósitos de fomentar um grau de complementaridade comercial ainda limitado, além da criação de mecanismos para prover os recursos requeridos para investimentos de longo prazo.

Outra diferença marcante entre as duas regiões está associada ao grau de variação entre as paridades das moedas dos países envolvidos. Como mostra a Tabela 2, o coeficiente de variação médio entre as taxas de câmbio nominais dos países asiáticos no período de 1998 a 2007 foi bem menor que o verificado entre os países latino-americanos e caribenhos: o coeficiente de variação mais alto observado dentre os países asiáticos corresponde a menos da metade do registrado na América Latina e Caribe. Maior estabilidade nas paridades aumenta as possibilidades de intercâmbio entre os países envolvidos, ao reduzir os riscos envolvidos na atividade comercial, e ampliar a margem para a cooperação monetária e financeira.

Tabela 2: Coeficientes de Variação das Taxas de Câmbio Nominais (1998-2007)

\begin{tabular}{|c|c|}
\hline 14 Países da Ásia* & 14 Países da América Latina ** \\
\hline Coeficiente de Variação Médio: 0.085 & Coeficiente de Variação Médio: 0.201 \\
\hline Coeficiente de Variação mais Baixo: & Coeficiente de Variação mais Baixo: \\
0.029 (Camboja) & 0.043 (Guatemala) \\
\hline Coeficiente de Variação mais Alto: & Coeficiente de Variação mais Alto: \\
0.233 (Laos) & 0.483 (Venezuela) \\
\hline
\end{tabular}

(*), Brunei Darussalam, Camboja, China, Cingapura, Coreia, Filipinas, India, Indonésia, Japão, Laos, Malásia, Paquistão, Tailândia, Vietnã

(**) Argentina, Bolívia, Brasil, Chile, Colômbia, Costa Rica, Guatemala, Honduras, México, Nicarágua, Paraguai, Peru, Uruguai, Venezuela.

Fonte: IMF, International Financial Statistics, diversos números.

Outro aspecto de destaque no caso asiático é que os países participantes dos esforços de cooperação monetária e financeira podem dispor de um volume de reservas internacionais expressivo para sustentar os esforços de cooperação. A Tabela 3 a seguir ilustra esse ponto. É digno de destaque, em particular, o potencial representado pelas economias da China e do Japão, seguidas pela Coreia.

Boa parte desses recursos se encontra aplicada fora da região, sobretudo em títulos do Tesouro norte-americano. Segundo dados do Departamento do 
Tesouro $^{18}$ em dezembro de 2008 a China mantinha não menos de US\$ 730 bilhões de suas reservas (48\%) aplicados nesses títulos, o Japão US\$ 626 bilhões $(66 \%)$ e a Coreia US\$ 31 bilhões $(12 \%)$.

Essas três economias têm papel de destaque na promoção da coordenação monetária e financeira regional. Esta é uma diferença notável em relação à experiência latino-americana, onde não existem economias com fôlego financeiro comparável para funcionarem como 'âncoras' de um processo de coordenação semelhante.

Tabela 3: Reservas Internacionais de Países Asiáticos

e Latino-Americanos Selecionados - 2000-2007

\begin{tabular}{|c|c|c|c|c|c|}
\hline $\begin{array}{l}\text { País } \\
\text { Ásia }\end{array}$ & $\begin{array}{c}\text { Reservas em } \\
\text { Dezembro } \\
\text { de } 2007 \\
\text { (US\$ milhões) }\end{array}$ & $\begin{array}{c}\text { Variação (\%) entre } \\
\text { Dezembro/00 e } \\
\text { Dezembro/07 }\end{array}$ & $\begin{array}{c}\text { País } \\
\text { América } \\
\text { Latina }\end{array}$ & $\begin{array}{c}\text { Reservas em } \\
\text { Dezembro } \\
\text { de } 2007 \\
\text { (US\$ milhões) }\end{array}$ & $\begin{array}{c}\text { Variação (\%) } \\
\text { entre } \\
\text { Dezembro/00 } \\
\text { e Dezembro/07 }\end{array}$ \\
\hline Brunei & 667 & 63 & Argentina & 44682 & 78 \\
\hline Camboja & 1807 & 260 & Bolívia & 4554 & 392 \\
\hline China & 1530280 & 809 & Brasil & 179433 & 453 \\
\hline Cingapura & 162957 & 103 & Chile & 16837 & 12 \\
\hline Coreia & 262150 & 173 & Colômbia & 20767 & 133 \\
\hline Filipinas & 30211 & 131 & C. Rica & 4114 & 212 \\
\hline India & 266988 & 604 & Guatemala & 4130 & 136 \\
\hline Indonésia & 54976 & 93 & Honduras & 2528 & 92 \\
\hline Japão & 952784 & 168 & México & 87109 & 145 \\
\hline Laos & 533 & 283 & Nicarágua & 1103 & 126 \\
\hline Malásia & 101019 & 256 & Paraguai & 2462 & 223 \\
\hline Paquistão & 14044 & 828 & Peru & 26856 & 696 \\
\hline Tailândia & 85221 & 166 & Uruguai & 4114 & 66 \\
\hline Vietnã & 23479 & 587 & Venezuela & 24196 & 85 \\
\hline $\begin{array}{l}\text { Média(*) } \\
14 \text { países }\end{array}$ & 249080 & 323 & & 30206 & 197 \\
\hline
\end{tabular}

$\left({ }^{*}\right)$ não ponderada

Fonte: http:// www.imfstatistics.org.

No caso dos países latino-americanos não apenas o volume de reservas é bastante inferior (pouco mais de $10 \%$ do total asiático), como seu aumento entre 2000 e 2007 foi em média bem menor do que o observado entre os asiáticos.

Para os asiáticos, os esforços de promoção de um mercado regional de

${ }^{18}$ Disponíveis em http://www.treas.gov/tic/mfh.txt. 
capitais refletiram a tentativa de atrair de volta recursos aplicados no resto do mundo. ${ }^{19}$ De fato, como mostra o Gráfico 2, os países asiáticos são exportadores líquidos de recursos (poupança externa negativa). Já no caso dos países latino-americanos, ${ }^{20}$ o percentual de poupança externa em relação ao PIB é sistematicamente positivo, refletindo a necessidade de recursos externos para financiar seu processo de crescimento. Nesse período, em apenas poucos casos (Argentina, Brasil, Chile, Uruguai e Venezuela) se verificou transferência de recursos ao exterior nos oito anos considerados.

A média (não ponderada) dos Saldos em Transações Correntes dos países asiáticos considerados nesses oito anos foi de $4,8 \%$ do PIB, indicando uma tendência líquida conjunta a exportar poupança. Para o conjunto de países latino-americanos essa mesma média foi de $-3.0 \%$ do PIB, refletindo o uso recorrente de poupança externa para financiar seu dinamismo.

Gráfico 2: Poupança Externa - Ásia e América Latina-2000-2007

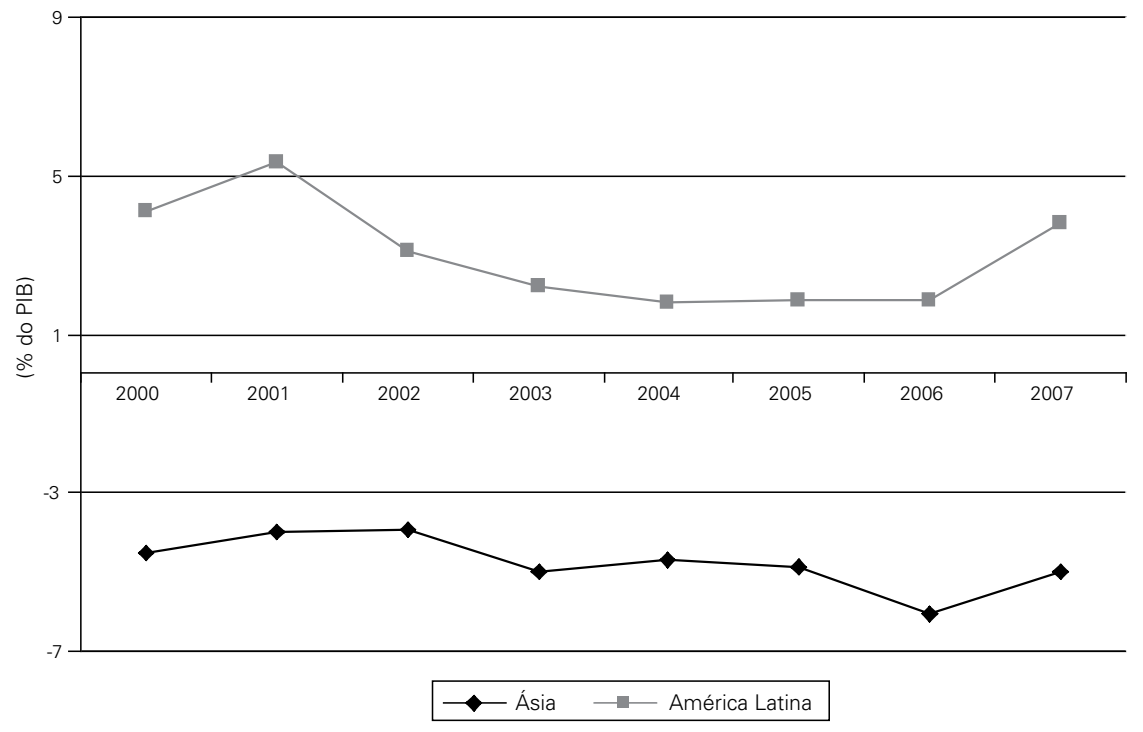

Fonte: World Development Indicators On Line (http://ddp-ext.worldbank.org).

\footnotetext{
${ }^{19}$ Embora em situações de crise essa afirmativa possa demandar alguma qualificação: segundo o Departamento do Tesouro dos EUA, entre setembro de 2007 e setembro de 2008 - período que compreende a fase mais aguda da mais recente crise financeira - diversos países asiáticos reduziram sua exposição a títulos do Tesouro, mas a China aumentou em $25 \%$ seu estoque desses papéis, e o Japão reduziu em apenas $3 \%$ suas posições.

${ }^{20}$ De acordo com o Departamento do Tesouro em dezembro de 2008 dos países latino-americanos apenas o Brasil, com US\$ 127 bilhões, o México, com US\$ 35 bilhões e o Chile, com US\$ 15 bilhões, apareciam entre os principais detentores de títulos do Tesouro. Nos doze meses até setembro de 2008 os três países aumentaram suas posições, com variações de entre quase $90 \%$ no caso do Chile e $14 \%$ no caso do México.
} 
Temos, portanto, duas situações bem distintas: na Ásia, uma participação das transações regionais nas exportações que é o dobro do observado na América Latina, e uma disponibilidade de recursos que gera a necessidade de busca de oportunidades, encontradas em sua maior parte fora da região, sendo o principal desafio criar as condições para atrair de volta esses recursos. $\mathrm{Na}$ América Latina, ao contrário, há uma sistemática e expressiva demanda por recursos externos, identificados como condição necessária para ajudar a financiar o processo de crescimento, facilitar o aprofundamento do processo de integração regional e prover liquidez em divisas.

É com essa dupla perspectiva em mente que se devem analisar as iniciativas de cooperação monetária e financeira nas duas regiões.

A Tabela 4 a seguir mostra os principais indicadores do mercado asiático de títulos. Os dados estão disponíveis para apenas nove dos 14 países considerados.

A Tabela 4 mostra que o tamanho do mercado regional de títulos nesses nove países aumentou em forma expressiva, sobretudo na atual década (cresceu três vezes e meia), graças sobretudo às contribuições dos mercados da China, Coreia e particularmente Japão.

É notável que esse mercado seja formado predominantemente por títulos soberanos, sendo a participação privada relativamente limitada, e bastante reduzida em alguns casos, como no Paquistão, Filipinas, Indonésia e Tailândia. ${ }^{21}$

Tabela 4: Ásia - Tamanho do Mercado Local de Títulos - 1990 a 2007

\begin{tabular}{|c|c|c|c|c|c|}
\hline & \multicolumn{3}{|c|}{ Mercado Total (US\$ bilhões) } & \multicolumn{2}{c|}{ Títulos Públicos (\%) } \\
\hline & 1990 & 2000 & 2007 & 2000 & 2007 \\
\hline China & 20 & 202 & 1687 & 54.7 & 67.4 \\
\hline Cingapura & 11 & 42 & 97 & 59.5 & 70.0 \\
\hline Coreia & 12 & 378 & 1077 & 30.2 & 43.3 \\
\hline Filipinas & 11 & 21 & 54 & 99.0 & 97.1 \\
\hline Indonésia &.. & 54 & 86 & 95.6 & 89.2 \\
\hline Japão & 2762 & 2702 & 8856 & 63.4 & 80.7 \\
\hline Malásia & 33 & 75 & 179 & 37.8 & 39.0 \\
\hline Paquistão & 12 & 27 & 43 & 100.0 & 100.0 \\
\hline Tailândia & 9 & 31 & 138 & 54.3 & 70.1 \\
\hline TOTAL & 2870 & 3532 & 12217 & & \\
\hline
\end{tabular}

Fonte: BIS Quarterly Review, March 2009. (..) não disponível

$\mathrm{Na}$ América Latina (Tabela 5) também o mercado local de títulos aumentou em proporções significativas nesse período, tendo mais do que triplicado

\footnotetext{
${ }^{21}$ Segundo Borensztein, Eichengreen e Panizza (2006), no Leste Asiático os títulos privados correspondiam em 2004 a 8,9\% do PIB regional. Na América Latina esse percentual no mesmo ano era de 2,7\%.
} 
em valor, com ampliação nos sete países para os quais existe informação disponível. À semelhança da Ásia, na América Latina esse mercado é predominantemente de títulos públicos (como de resto se observa igualmente nos países africanos e nas economias menores da Europa). De fato, entre 2000 e 2007 o peso relativo dos títulos públicos aumentou na Argentina, Peru e Venezuela.

As Tabelas 4 e 5 revelam que a dimensão do mercado regional de títulos na América Latina é bastante menos expressiva do que entre os países da Ásia: em 2007 representava apenas $15 \%$ do valor transacionado na Ásia. Além disso, é interessante notar que na América Latina o crescimento do mercado de títulos foi aparentemente mais intenso na década de 1990 (quando cresceu sete vezes) do que na presente década, ao contrário da experiência asiática, em que o maior dinamismo teve lugar nos últimos anos. ${ }^{22}$

Tabela 5: América Latina - Tamanho do Mercado Local de Títulos - 1990 a 2007

\begin{tabular}{|c|c|c|c|c|c|}
\hline & \multicolumn{3}{|c|}{ Mercado Total (US\$ bilhões) } & \multicolumn{2}{c|}{ Títulos Públicos (\%) } \\
\hline & 1990 & 2000 & 2007 & 2000 & 2007 \\
\hline Argentina & 17 & 47 & 76 & 70 & 83 \\
\hline Brasil &.. & 314 & 953 & 84 & 69 \\
\hline Chile & 7 & 35 & 43 & 61 & 34 \\
\hline Colômbia & 1 & 17 & 52 & 99 & 98 \\
\hline México & 50 & 128 & 353 & 60 & 54 \\
\hline Peru &.. & 6 & 22 & 65 & 79 \\
\hline Venezuela &.. & 9 & 147 & 92 & 98 \\
\hline & & & & & \\
\hline Total & 75 & 556 & 1646 & & \\
\hline
\end{tabular}

Fonte: BIS Quarterly Review, March 2009.

(..) dado não disponível

Parte das diferenças entre esses dois grupos de países tem a ver com o próprio histórico dessas economias, com os asiáticos buscando soluções regionais para lidar com problemas de liquidez em situações de crise externa, e os latino-americanos priorizando a provisão de capitais de longo prazo para fortalecer e aprofundar a complementariedade produtiva e o processo de integração regional.

Em situações de crises externas os países latino-americanos buscaram apoio de maneira bem mais intensa e sistemática junto ao FMI.Segundo a Tabela 6 e o Gráfico 3, uma quantidade bem maior de países latino-americanos

\footnotetext{
${ }^{22}$ Essa observação deve ser vista com as devidas reservas, uma vez que reflete as informações na base de dados consultada. Ao menos no caso do Brasil, é sabido que foi na segunda metade da presente década que o mercado de capitais superou todos seus recordes (Leal e Carvalhal, 2008).
} 
utilizou essa alternativa, em maior número de operações, e envolvendo valores mais expressivos que no caso dos países asiáticos.

Quando a crise de 1997 mostrou a incapacidade do FMI em prover recursos nos montantes requeridos pelos países asiáticos afetados, isso consolidou uma tendência que já se observava há algum tempo, de busca de soluções alternativas. Os países latino-americanos, ao contrário, apresentaram um certo 'risco moral', de posição acomodada, ao buscar nos recursos institucionais do Fundo a solução para sua restrição de liquidez.

Tabela 6 - Montantes e Número de Operações com o FMI — 1984-2007

\begin{tabular}{|c|c|}
\hline \multicolumn{2}{|c|}{ Operações com o FMI em 1984 - 2007* } \\
\hline Ásia & América Latina \\
\hline \multicolumn{2}{|c|}{ Valor (DES milhões) } \\
\hline 26011 & 66054 \\
\hline \multicolumn{2}{|c|}{ Número de Operações por País } \\
\hline China -1 & Argentina -17 \\
\hline Coreia -6 & Bolívia - 17 \\
\hline Filipinas -14 & Brasil - 9 \\
\hline Índia -3 & Chile -6 \\
\hline Tailândia - 5 & Equador -13 \\
\hline \multirow[t]{4}{*}{ Vietnã -6} & México - 12 \\
\hline & Peru -3 \\
\hline & Uruguai -3 \\
\hline & Venezuela -4 \\
\hline
\end{tabular}

(*)Desembolso Total — GRA e Empréstimos (PRGF/ESAF/SAF/Trust Fund).

Fonte: http://imf.org/external/country/index.htm.

Gráfico 3: Ásia e América Latina - Operações com o FMI em 1984-2007

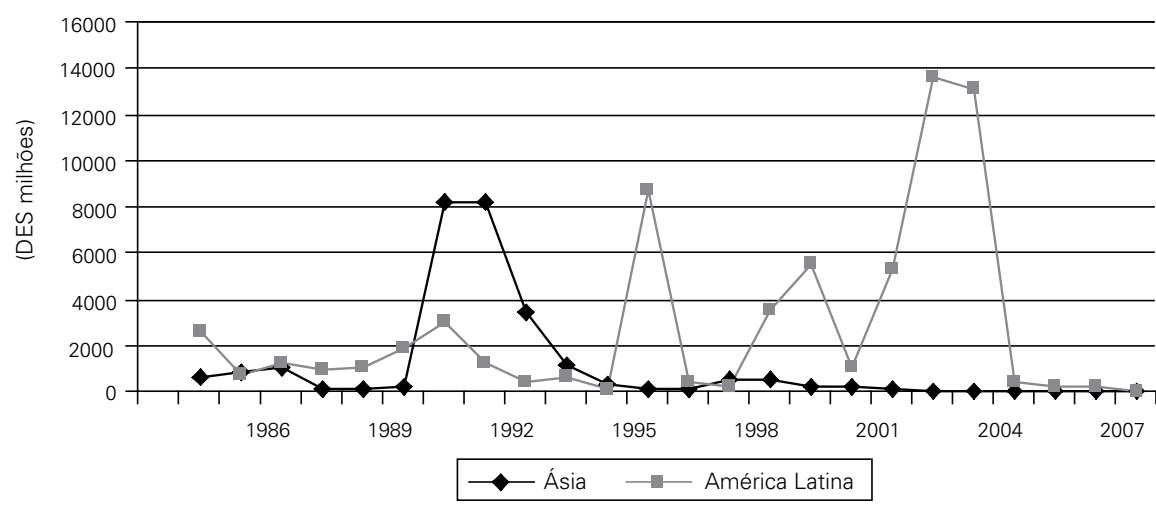

Fonte:http:/imf.org/external/country/index.htm. 
A consideração sobre a experiência passada desses dois grupos de países é de crescente relevância quando esse debate começa a ganhar importância, tendo em vista a necessidade de dispor de mecanismos de provisão de crédito de longo prazo para financiar projetos, assim como de instrumentos de provisão de liquidez em situações de risco.

\section{CONSIDERAÇÕES FINAIS}

Este artigo procurou tornar explícito que existem diferenças expressivas entre as experiências dos países asiáticos e latino-americanos no que se refere à cooperação monetária e financeira. A intensificação dos esforços desenvolvidos na América Latina, na promoção da complementaridade entre as economias da região, certamente pode se beneficiar do aprendizado a partir da experiência asiática.

O que procuramos mostrar aqui é que o exemplo asiático deve boa parte do seu sucesso a condições específicas que não são encontradas hoje na América Latina. Entre outras, destacam-se a existência de economias na região que aportam a maior parte dos recursos necessários para a criação e o desenvolvimento de mercados regionais de títulos, a disponibilidade de grandes volumes de reservas de divisas, um grau expressivo de intercâmbio comercial entre os países vizinhos, estabilidade nas paridades entre as moedas da região, e uma institucionalidade que possibilita o intercâmbio frequente de informações conjunturais e a análise preventiva de possíveis choques externos.

A percepção de que conviver com economias vizinhas em situação problemática pode afetar a maior parte das economias de uma mesma região tem motivado um conjunto de iniciativas de cooperação na Ásia. Essa consciência é menos nítida na América Latina, o que é um reflexo do próprio baixo grau de intercâmbio entre as economias da região.

A estabilidade das paridades entre as moedas regionais é claramente um ativo importante no caso asiático. No âmbito latino-americano o pouco que se conseguiu avançar nesse sentido no início da presente década corre o risco de se dissipar, pela baixa sincronia entre as decisões de política econômica dos diversos países, e o próprio grau reduzido de transações comerciais ao nível regional. O acordo Brasil-Argentina para uso de moedas nacionais no intercâmbio bilateral é uma notável exceção, mas ainda muito recente para que se possam confirmar as expectativas generalizadas de resultados positivos.

Nos últimos anos houve acúmulo de um volume importante de reservas de divisas internacionais por parte dos países latino-americanos, mas o montante permanece diminuto em comparação com os números encontrados no continente asiático. Isso significa uma capacidade bem mais reduzida de promoção de um mercado regional de títulos, e uma restrição para buscar no nível regional os recursos requeridos em situações de baixa liquidez externa.

$\mathrm{O}$ custo de reter volumes expressivos de reservas tem provocado debates 
sobre o nível ótimo a ser mantido. A experiência asiática é sugestiva de que o custo de carregamento de um dado nível de reservas pode ser reduzido, sem prejuízo da disponibilidade potencial de liquidez, por mecanismos de acesso compartilhado aos recursos dos países participantes. Iniciativas desse tipo são incipientes na América Latina.

O comércio regional latino-americano tem se recuperado, mas permanece a níveis mais limitados do que em outras regiões. Um mecanismo útil para a promoção das transações intrarregionais (o CCR) continua já há alguns anos com um grau de contribuição muito baixo. Haveria que se pensar em sua reativação de maneira bem mais intensa.

$\mathrm{O}$ uso mais intenso de recursos do FMI pelos latino-americanos, em comparação com os asiáticos, explica em parte a diferença entre os dois grupos de países, quanto ao empenho em construir opções regionais de fontes de divisas.

Situações extraordinárias, como as geradas em momentos de crises, são propícias para mudanças expressivas, difíceis de serem adotadas em tempos de normalidade. A experiência asiática indica algumas lições, que poderiam ser consideradas na América Latina.

Primeiro, a soma de reservas em algum mecanismo de tipo fundo regional e/ou repasse de recursos entre países é comprovadamente importante. Um nível desejável de reservas pode ter custo mais baixo se puder ser obtido a partir do acesso compartilhado a recursos dos países parceiros. Este deveria ser um item da agenda de políticas, sobretudo num contexto em que o sistema financeiro internacional não dispõe de mecanismos suficientes de regulação nem de volume de recursos suficiente.

Segundo, é fundamental dispor de fontes de financiamento a baixo custo para projetos de longo prazo. O desenvolvimento de um mercado regional de capitais é uma condição fundamental. A América Latina não dispõe de uma China ou um Japão para prover uma parte expressiva dos recursos requeridos nesse processo. E tem optado com muito mais ênfase que os asiáticos por criar instituições para a provisão de crédito de longo prazo. Há que se pensar em instrumentos mais ambiciosos, mas não é claro que isso implique necessariamente a criação de novas instituições.

Terceiro, do ponto de vista da integração regional há que se atuar também do lado da demanda. Reativar mecanismos como o Convênio de Crédito Recíproco, parece ser uma solução natural. O 'swap' de moedas e/ou a possibilidade de utilizar moedas nacionais nas trocas entre vizinhos são igualmente instrumentos que reduzem custos de transação e fomentam o comércio.

Por último, mas não menos importante, como fonte de estímulo à deman$\mathrm{da}$, o ideal seria assegurar estabilidade entre as paridades. $\mathrm{O}$ baixo grau de integração é um elemento complicador para tanto. Nesse caso, a alternativa é enfatizar a preservação de baixas taxas de inflação, como forma de ampliar a probabilidade de estabilidade nas taxas de câmbio.

Finalmente, um aprendizado importante da experiência asiática é a im- 
portância de contar com mecanismos institucionalizados para o monitoramento compartilhado da conjuntura internacional e regional. Ações preventivas são quase sempre mais baratas que intervenções em situações de crise.

\section{REFERÊNCIAS BIBLIOGRÁFICAS}

BORENSZTEIN, E., B. EICHENGREEN, e U. PANIZZA (2006), "Building Bond Markets in Latin America”, February, in www.econ.berkeley.edu/ eichengr/research/build_bond_mkt_LA.pdf

CEMLA (Centro de Estudios Monetarios Latinoamericanos) (1992) Cuarenta años del Centro de Estudios Monetarios Latinoamericanos 1952-1992, México.

COOPER, C. e B.MASSELL (1965), “Toward a general theory of customs unions for developing countries", The Journal o Political Economy, vol. 73, N5, October.

CULPEPER, R. (2006), "Reforma de la arquitectura financiera mundial: el potencial de las instituciones regionales", Cooperación financiera regional, José Antonio Ocampo (org.), Santiago de Chile, Comisión Económica para América Latina y el Caribe (CEPAL).

EICHENGREEN, Barry e Ricardo HAUSMANN (1999), "Exchange rates and financial fragility", NBER Working Paper, $\mathrm{N}^{\circ} 7418$.

FRITZ, Barbara e Laurissa MÜHLICH (2006), “Regional monetary integration among developing countries: new opportunities for macroeconomic stability beyond the theory of optimum currency areas?", Working Papers, $\mathrm{N}^{\circ} 38$, Hamburg, Giga-German Institute of Global and Area Studies, December.

GRAUWE, P. de (1992), The economics of monetary integration, Oxford, Oxford University Press.

HEIDRICH, Pablo (2008), "A Região do Leste Asiático: do multilateralismo ao bilateralismo", Revista Brasileira de Comércio Exterior, ano XXII, N94, janeiro/março.

ISHIYAMA, Y. (1975), "The theory of optimum currency areas: a survey", IMF Staff Papers, July.

LEAL R. e A.CARVALHAL (2008), O Financiamento Externo no Ciclo Recente da Economia Brasileira, IPEA, Texto para Discussão No.1384

LIPSEY, R. (1960), “Theory of customs union - a general survey”, Economic Journal, vol. 70, September.

NUSSBAUM, Arthur (1944), "International monetary agreements", The American Journal of International Law, 38 (2), April <Acesso em: 4. de agosto de 2008> <http://www.jstor.org/ stable/2192695>.

OCAMPO, José Antonio (2006), “La cooperación financiera regional: experiencias y desafíos”, Cooperación financiera regional, José Antonio Ocampo (org.), Santiago de Chile, Comisión Económica para América Latina y el Caribe (CEPAL).

PARK, Y. C. (2006), “Integración financiera regional en Asia Oriental: desafíos y perspectivas”, Cooperación financiera regional, José Antonio Ocampo (org.), Santiago de Chile, Comisión Económica para América Latina y el Caribe (CEPAL).

PREBISCH, Raul (1987), "Las cinco etapas de mi pensamiento sobre el desarrollo", Raul Prebisch: un aporte al estudio de su pensamiento, Santiago de Chile, Comisión Económica para América Latina y el Caribe (CEPAL).

RAJAN, Ramkishen (2002), Examining the links between trade and monetary regionalism, University of Adelaide, October, mimeo.

RUTTIMANN, Carlos e outros (2008), “CCR: seu papel no financiamento à Infraestrutura”, Revista do BNDES, 14 (29), junho.

SOHN, Injoo (2007), “East Asia's counterweight strategy: Asian financial cooperation and evolving international monetary order", G-24 Discussion Paper Series, N 44, UNCTAD, March.

VOLZ, Ulrich (2008), "Asian Monetary Fund, take two”, Far Eastern Economic Review, 171 (6), June <http://feer.com/economics/2008/june/an-asian-monetary-fund-second-try> 